\title{
A ÁGUA COMO FONTE DE CONHECIMENTO: UMA PROPOSTA NO ENSINO MÉDIO INTEGRADO
}

\author{
Jéssica De Góes Bilar, Rômulo Hohemberger, Renato Xavier Coutinho* \\ *E-mail: renato.coutinho@iffarroupilha.edu.br \\ Instituto Federal Farroupilha, Campus São Vicente do Sul, Brasil \\ DOI: 10.15628/rbept.2020.8833 \\ Artigo submetido em jul/2019 e aceito em fev/2020
}

\begin{abstract}
Resumo
A água é um tema constantemente abordado em sala de aula, devido a sua importância e interferência no meio ambiente, porém muitas vezes ele é tratado de maneira isolada e descontextualizada. Assim, o objetivo desta pesquisa é analisar a implantação de um projeto interdisciplinar tendo como tema a água, observando as percepções de alunos e professores ao longo do processo. Esta proposta é denominada "Prática Profissional Integrada", realizado no Instituto Federal Farroupilha, envolvendo o curso Técnico Integrado de Agropecuária. Este projeto é composto por três ações (conjunto de palestras de sensibilização para o tema e 2 dias de campo) as quais envolvem todos os estudantes do curso e professores das áreas técnicas e básicas. Através das ações desenvolvidas foi possível verificar um aumento do interesse dos alunos pelos conteúdos trabalhados e a integração entre as disciplinas e áreas de conhecimento, possibilitando uma preocupação e responsabilidade quanto ao consumo da água.
\end{abstract}

Palavras-chave: Prática Profissional Integrada; Recursos hídricos; Meio ambiente.

\section{WATER AS A SOURCE OF KNOWLEDGE: A PROPOSAL IN INTEGRATED AVERAGE EDUCATION}

\begin{abstract}
Water is an issue that is constantly addressed in the classroom, because of its importance and interference with the environment, although it is often treated in an isolated and decontextualized way. Thus, the design is seen as an interdisciplinary application that has the theme of water, observing the perceptions of students and teachers throughout the process. This is called "Integrated Professional Practice", held at the Federal Institute Farroupilha, with the Integrated Agricultural Technical Course. This project consists of three actions to raise awareness of the theme and two days of work, as a complete stage of awareness for the theme and two days of field. From a series of prepared actions, the areas of knowledge can be improved and the areas of knowledge, power of understanding and power of water awareness.
\end{abstract}

Keywords: Integrated Professional Practice;Water resources; Environment. 


\section{INTRODUÇÃO}

A água tem sido utilizada frequentemente como tema para práticas interdisciplinares nas escolas, por diversos fatores, sendo o principal deles a relação intrínseca com a vida, conforme afirma Bacci e Pataca (2008), para uma educação efetiva é necessário desenvolver uma visão integrada do mundo que nos cerca, uma visão que nos leve a compreender as diversas esferas (hidrosfera, biosfera, litosfera e atmosfera) e suas inter-relações, bem como as interferências geradas pelo homem no meio em que vive.

Partindo desta concepção Hofstatter, De Oliveira e Souto (2016), relatam que a maior finalidade da escola deveria ser a de promover uma educação comprometida com a formação integral de estudantes. Com este intuito foram criados no ano de 2008 os Institutos Federais de Educação, Ciência e Tecnologia, a partir dos Centros Federais de Educação Tecnológica (Cefet), antes escolas agrotécnicas federais e escolas técnicas vinculadas às universidades, formando e qualificando cidadãos com vistas na atuação profissional nos diversos setores da economia, com ênfase no desenvolvimento socioeconômico local, regional e nacional, além de promover a integração e a verticalização da educação básica à educação profissional (Lei nำ11.892, de 29 de dezembro de 2008).

Deste Modo, a educação profissional, segundo Ciavatta e Ramos (2012), é o primeiro sentido que se atribui a concepção de formação humana, integrando todos os sentidos da vida, trabalho, ciência e cultura. Mediante isto, o ensino integrado tem como princípio aspectos da formação humana, ensino contextualizado, interdisciplinar, ensino pela pesquisa e o trabalho como princípio educativo.

Desta forma, ensino integrado é apresentado de forma desfragmentada e humanizada, descrito por Araújo e Frigotto (2015) como:

Um projeto que traz um conteúdo político-pedagógico engajado, comprometido com o desenvolvimento de ações formativas integradoras (em oposição às práticas fragmentadoras do saber), capazes de promover a autonomia e ampliar os horizontes (a liberdade) dos sujeitos das práticas pedagógicas, professores e alunos, principalmente (2015, p. 63).

Assim, a Prática Profissional Integrada (PPI), prevista na organização curricular dos cursos técnicos integrados, pretende articular horizontalmente 0 conhecimento dos três anos do curso oportunizando o espaço de discussão e um espaço aberto para entrelaçamento entre as disciplinas e incentivando à pesquisa como princípio educativo, promovendo a interdisciplinaridade e a indissociabilidade entre ensino, pesquisa e extensão através do incentivo à inovação tecnológica (IFFar, 2014). 
Cabe-nos ressaltar aqui que dentre os cursos técnicos integrados que são distribuídos entre os 11 campi do Instituto Federal Farroupilha (IFFar), nos campi de Alegrete, Frederico Westphalen, Júlio de Castilhos, Santo Augusto e São Vicente do Sul é ofertado o curso técnico em Agropecuária, integrado ao Ensino Médio. Este tem como objetivo formar técnicos em agropecuária capazes de fazer frente às necessidades do mundo do trabalho, em constante evolução tecnológica.

Neste contexto, diversos temas emergem como possíveis articuladores do desenvolvimento dessas práticas interdisciplinares e que contemplem as necessidades técnico-formativas. Podemos citar os Temas Transversais, dispostos no PCN, os quais, apesar de constarem nos documentos oficiais desde 1997, possuírem um caráter agregador das disciplinas (BRASIL, 1997), até o presente, não foram implementados de maneira efetiva na escola (COUTINHO et al. 2014, p. 771).

Logo, sugere-se como um tema articulador, a água, porém ao tratar dela enquanto conteúdo escolar, a maioria das abordagens fica limitada à disciplina de biologia, tratando-a de maneira isolada e descontextualizada. Deste modo, demonstrando apenas um ciclo genérico, não havendo uma aproximação com o que o aluno está acostumado a observar no cotidiano (DE SANTANA; DE SOUZA; SHUVARTZ, 2012, p. 004671).

Assim sendo, salientamos a importância de discutir no espaço escolar 0 tema água, pela sua abundância e distribuição no Planeta, pela sua proximidade do aluno (QUADROS, 2004, p. 27), além das implicações da mesma nos aspectos sociais, ambientais e econômicos. Ademais, a abordagem interdisciplinar a partir da temática, "compreende troca e cooperação, uma verdadeira integração entre as disciplinas de modo que as fronteiras entre elas se tornem invisíveis para que a complexidade do objeto de estudo se destaque" (AUGUSTO; CALDEIRA, 2007, p. 141).

Para tanto, o presente estudo se propõe a analisar uma prática interdisciplinar com o tema água, observando o desenvolvimento da prática enquanto impacto na percepção dos alunos ao longo do processo, evidenciando assim, a uma construção sólida da aprendizagem, a partir do ensino pela pesquisa.

\section{METODOLOGIA}

\section{Estudo realizado e abordagem utilizada}

O presente estudo apresenta caráter qualitativo, sendo definido por Gerhardt e Silveira (2009) como a qual não se preocupa com representatividade numérica, mas, sim, com 0 aprofundamento da compreensão de um grupo social e de uma organização, se baseou na participação dos grupos integrantes da prática, bem como o desenvolvimento técnico e profissional perceptivo durante as estações apresentadas. 
Além disso, a abordagem se caracteriza enquanto uma pesquisa-ação, em que Engel (2000) aponta esta metodologia como um tipo de pesquisa participante engajada, em oposição à pesquisa tradicional, que é considerada como "independente", "não-reativa" e "objetiva", buscando a compreensão como parte da prática. Neste caso, a presente pesquisa se enquadra nestas perspectivas, pois se buscou a transformação da realidade através de intervenções e reflexões a partir da prática.

Para Franco (2005), quando se opta por trabalhar com pesquisa-ação, por certo tem a convicção de que pesquisa e ação podem e devem caminhar juntas quando se pretende a transformação da prática. Logo, a prática é o que move a pesquisa, assim tornando-a concreta e centralizada nos ideais propostos.

\section{Sujeitos da pesquisa}

Os participantes envolvidos nesta atividade foram alunos do curso Técnico de Agropecuária Integrado ao Ensino Médio do Instituto Federal Farroupilha campus São Vicente do Sul/RS, com participação de todas as turmas do segundo e terceiro ano, totalizando 220 alunos.

Além disso, houve a participação da maioria dos professores do curso, tanto das áreas técnicas como das básicas, envolvidos em todas as etapas da proposta realizada, atuando como orientadores dos trabalhos e/ou avaliadores.

\section{Coleta e análise dos dados obtidos}

A coleta de dados se deu a partir da aplicação de um questionário avaliativo, contendo duas questões, sendo estas descritivas, buscando compreender quais foram os aprendizados obtidos ao longo da proposta. A análise destes dados ocorreu de forma qualitativa, a qual para Thiollent (2008) obtém os dados representativos de ordem cognitiva, sociológica e politicamente fundamentada, com possível controle ou retificação de suas distorções no decorrer da investigação.

Além disso, após as atividades os educandos responderam a algumas questões sobre a atividade que desenvolveram. Para analisar essas respostas, utilizou-se a análise do conteúdo, descrita por Bardin (2016), a qual é composta de três etapas: a pré-análise, a exploração do material e o tratamento dos resultados. Nesse contexto, durante a etapa de pré-análise, os instrumentos da pesquisa foram lidos algumas vezes e, na sequência, deu-se início a codificação. Logo, na exploração do material, foram identificadas as categorias ou unidades de análise, propondo-se ao próximo passo (tratamento dos resultados) de agrupar as respostas com mesmo sentido.

Os resultados obtidos referem-se à participação e ao conhecimento adquirido pelos educandos ao longo da prática profissional integrada, desde as reuniões de planejamento até a elaboração da revista digital. 


\section{RESULTADOS E DISCUSSÕES}

\section{Construção e descrição da proposta}

Inicialmente ocorrem as reuniões de planejamento, que caracterizaram a primeira etapa, e a principal para a definição do tema, através do diálogo entre os professores. Na sequência, ocorreu a palestra de sensibilização, onde os professores de diferentes áreas (básicas e técnicas) introduziram a temática "Água como fonte de conhecimento" a partir de diferentes olhares, com intuito de proporcionar a reflexão dos educandos sobre o tema. As palestras apresentadas foram: 1) Água como fonte de conhecimento; 2) Distribuição e armazenagem: passado e presente; 3) Uso e aplicações da água na agropecuária; 4) Conflitos sobre a água.

Desta maneira, destacam-se as relações intrínsecas a água, bem como as suas aplicações no cotidiano, pois acredita-se que "algumas questões consideradas significativas no debate sociocientífico relacionado com a água deveriam ser incorporadas aos estudos escolares" (OTALARA; CARVALHO, 2011, p. 03).

Na sequência, após as palestras, planejaram-se as próximas etapas, na qual os educandos dos segundos e terceiros anos deveriam dividir-se em dois grupos por turma, e partir disto, decidir qual subtema nortearia a pesquisa de cada grupo, bem como a escolha dos professores/orientadores totalizando 16 grupos, entre o segundo e terceiro ano.

Após a organização dos grupos, definiram-se os dias de campo, os quais se caracterizam pelas apresentações dos trabalhos produzidos pelos educandos ao longo da proposta. Estes trabalhos são apresentados em forma de seminários ou oficinas, e são distribuídos em diferentes setores do campus. Abaixo, tem-se um fluxograma, o qual apresenta a organização da proposta e suas respectivas etapas. 


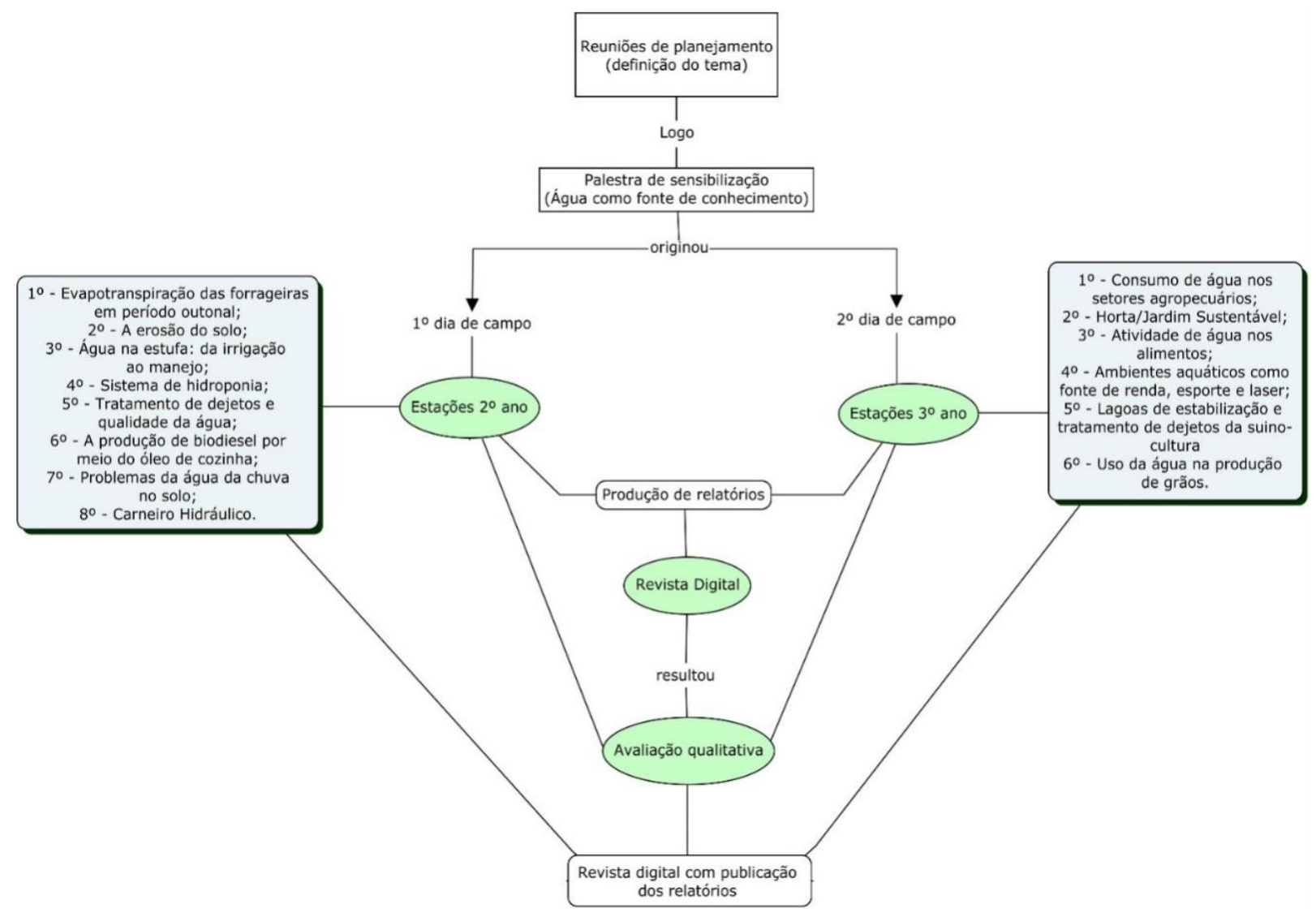

Para melhor compreender como se deu as apresentações dos trabalhos citados anteriormente, abaixo segue o desenvolvimento de cada um destes.

Primeiramente, no dia de campo interno, os alunos do segundo ano de Agropecuária apresentaram seus subtemas escolhidos, que deveriam estar relacionados ao tema principal. A apresentação ocorreu aos demais alunos do curso de Agropecuária (primeiro e terceiro ano). No total, apresentaram-se oito (08) estações, elencadas abaixo.

1. Evapotranspiração das forrageiras tropicais em período outonal: Ao pensar na oficina a ser realizada os educandos demonstraram uma preocupação com o gasto/desperdício da água na agricultura, mais precisamente no cultivo de forrageiras e sua respectiva produção, tendo como objetivo mostrar a capacidade de suportar uma unidade animal e o rendimento na produção de carne em um determinado período.

2. A erosão do solo: Diante a preocupação com a erosão hídrica que ocorre em grande parte das lavouras, o grupo desenvolve algumas formas de reduzir esse problema, como o sistema de plantio direto e a preservação das matas ciliares. Desta forma, foram apresentadas duas maquetes comparativas que demonstravam a ação da chuva em diferentes tipos de solos. Assim, o grupo demonstrou a importância do cuidado com o solo e o meio ambiente que o cerca.

3. Água na estufa: da irrigação ao manejo: A fim de se evitar o desperdício de água na irrigação das lavouras, o grupo teve como objetivo demonstrar 
sugestões de equipamentos rentáveis para cada tipo de cultura, bem como os efeitos da radiação e convecção nas estufas. Desta maneira, foram apresentados através de três minissistemas como funciona a irrigação, tanto na lavoura quanto na estufa.

4. Sistema de hidroponia: O tema apresentado tinha como principal objetivo demonstrar uma maneira sustentável para se manter uma horta em casa. Esta proposta evidenciou as vantagens, desvantagens e os sistemas usados, bem como a solução nutritiva usada na hidroponia, incluindo como é feita, os nutrientes que a constituem e sua manutenção. Além da explicitação das relações entre as disciplinas, como Química, Física, Biologia, Matemática e Olericultura.

5. Tratamento de dejetos e qualidade da água: A partir da reutilização da água descartada nas lagoas de estabilização, oriunda da moradia estudantil e do refeitório, este grupo apresentou como sugestão o que poderia ser feito quanto ao tratamento da mesma. Aproveitando o espaço institucional, foi apresentada a funcionalidade das lagoas de estabilização. Explanando como as impurezas químicas são separadas em cada fase até a sua devolução ao meio ambiente. Concluindo desta forma, o conhecimento sobre o tratamento da água e como ele ocorre dentro da realidade institucional.

6. A produção de biodiesel por meio do óleo de cozinha: Buscando alternativas para evitar a contaminação da água em pequenos atos do cotidiano, este grupo apresentou uma forma de reutilização do óleo de cozinha, que ao invés de ser descartado na pia foi usado como na produção de biodiesel. $\mathrm{Na}$ estação mostrou-se o biodiesel a partir da reação de transesterificação, em todas as fases que passa até chegar ao motor. Assim, integrando satisfatoriamente as disciplinas de química e mecanização agrícola.

7. Problemas da água da chuva no solo: Observando a relação da pluviosidade/perca de solo existente em lavouras, devido à exposição pelo manuseio incorreto deste, os educandos realizaram uma demonstração que exemplificasse tal atividade. Esta se deu a partir de uma demonstração prática, onde havia um solo protegido e outro desprotegido, relacionando a ação da chuva em ambos os solos. Conclui-se que o solo protegido é mais eficaz para as lavouras, pois assim não há lixiviação de solo nem de nutrientes.

8. Carneiro Hidráulico: $\mathrm{O}$ tema exposto teve como objetivo demonstrar a utilização de um mecanismo independente de energia para irrigação de lavouras, bem como a utilização de água de açudes sem o desperdício de água potável para a atividade do mesmo. Desta forma resultando na economia de energia e de recursos hídricos normalmente necessários para a agropecuária.

$\mathrm{Na}$ sequência, no dia de campo externo, os alunos do terceiro ano de Agropecuária apresentaram um total de seis (06) estações para a comunidade escolar e também às cidades vizinhas, localizadas na região Central do Rio Grande do Sul, como Santa Maria, Rosário do Sul, São Pedro do Sul, Mata e Unistalda. Estas trouxeram algumas de suas escolas, afim de que interagissem com as estações apresentadas no dia, totalizaram-se em média trezentos e vinte e seis (326) visitantes, entre alunos, professores e pais. Abaixo seguem as estações apresentadas ao público. 
1. Consumo de água nos setores agropecuários: Diante a preocupação com o consumo de água para a produção agrícola, produção animal e produção agroindustrial, este grupo desenvolveu a pesquisa afim de que se pudesse sensibilizar o maior número de pessoas quanto ao que é gasto em atividades somente do campo, desta maneira fazendo uma reflexão da importância da água para manutenção das plantas e animais, tratando-se da produção agropecuária brasileira e da instituição.

2. Horta/jardim vertical sustentável: A partir de um olhar econômico e sustentável, o grupo apresentou uma alternativa a qual reutilizando a água do ar condicionado e as garrafas pets se pudessem ter uma horta ou jardim altamente sustentável e prático, podendo ser construído em quintais, paredes e sacadas. A estação consistiu na apresentação teórico-prática do suporte vertical, o qual poderia utilizar a água da chuva captada para a irrigação da horta/jardim. Esses reaproveitamentos ajudam na parte econômica financeira e também a poupar a nossa água potável que está cada vez mais escassa.

3. Atividade de água nos alimentos: Sabe-se que para uma boa qualidade de vida deve-se ingerir 2 litros de água por dia entre outros cuidados fundamentais. Diante esta preocupação que devemos ter, o dado grupo esclareceu aos demais a quantidade de água que cada alimento possui, bem como a duração deste, a qual diferencia muito dependendo de sua quantidade de liquido apresentada. Além de explicações teóricas, foram apresentados diversos alimentos, tanto naturais quando industrializados, destacando a diferença que estes fazem na nossa alimentação e qualidade de vida.

4. Ambientes aquáticos como fonte de renda, esporte e laser: A água além de ser um bem provido da natureza, ela também proporciona formas de laser, como pesca e práticas de esportes aquáticos. Nesta estação os alunos realizaram demonstrações teóricas e práticas sobre vários esportes aquáticos que se pode praticar, bem como obter fonte de renda a partir de parques destinados ao cultivo da piscicultura, denominados pesque-pague. Utilizaram da canoagem como exemplo, praticada durante a oficina, em um açude localizado na própria instituição, bem como a exposição de uma maquete onde explicava como funcionava um parque pesque-pague.

5. Lagoas de estabilização para tratamento de dejetos da suinocultura: Preocupados com o a poluição da água e a falta de tratamento da mesma, o grupo teve como objetivo esclarecer dúvidas quanto ao tratamento das lagoas de estabilização utilizadas para o tratamento de dejetos da suinocultura. Esta era apenas usada como biofertilizantes. Para que o objetivo desta estação ficasse mais claro, a mesma foi instalada próxima ás lagoas de estabilização, onde os próprios integrantes do grupo trabalharam para a implementação da mesma, assim como da lagoa de plantas aquáticas, as quais funcionam como um anexo para o tratamento do chorume proveniente da lagoa Facultativa Anaeróbica.

6. Uso da água na produção de grãos: Sabendo que o alimento é indispensável para vida humana, para o tema abordando o grupo de estudantes apresentou os três grãos essenciais para uma alimentação saudável, relacionando o uso da água de forma sustentável sem prejudicar o meio em que vivemos, trazendo curiosidades e dados relacionados a produção 
de Arroz, Milho e Soja. A estação apresentou dados sobre a produtividade das culturas principalmente no Brasil e no Rio Grande do Sul, também, alguns métodos mais sustentáveis para produção eficiente de cada cultura.

Para finalizar as atividades, os trabalhos foram descritos a partir de um modelo de resumo para publicação em uma revista digital. Esta teve como objetivo expor todas as pesquisas realizadas de uma forma em que ficasse disponível a todos àqueles que se interessasse em saber mais detalhadamente sobre cada subtema apresentado. A revista digital foi publicada no site Joomag, de forma gratuita e de fácil acesso.

Ressalta-se que durante toda a prática a palavra água foi utilizada como uma "palavra problematizadora", porque a problematização aqui não é uma atividade vazia, ela possui um significado político, uma discussão da realidade vivida (SCHWARZ et al. 2016, p. 657). Desta forma, buscou-se trazer para o espaço institucional uma ampla discussão sobre a água, abordando soluções e resultados significativos para que possamos compartilhar desta e fazer das nossas atividades rotineiras algo mais responsável e consciente.

\section{Percepção dos estudantes sobre a prática profissional integrada (PPI)}

Após a ocorrência das estações e a elaboração da revista digital, foi aplicado um questionário aos estudantes através de um formulário online (google forms), neste pode-se melhor compreender a implicância do tema proposto na formação profissional dos mesmos, possibilitando um melhor compartilhamento de conhecimentos adquiridos.

Ao serem questionados sobre "O que você aprendeu com a PPI?", emergiram três categorias de respostas, as quais se encontram apresentadas na Tabela 1.

Tabela 1: Aprendizados gerados na PPI.

\begin{tabular}{ccc}
\hline Categorias & \multicolumn{1}{c}{ № de ocorrências } \\
\hline $\begin{array}{l}\text { A) } \begin{array}{l}\text { Integrar educandos } \\
\text { formação } \\
\text { conhecimento. }\end{array} \\
\text { do }\end{array}$ \\
\hline $\begin{array}{l}\text { B) Importância } \\
\text { preservação da água }\end{array}$ \\
\hline $\begin{array}{l}\text { C) Relações da água na } 8 \\
\text { agropecuária }\end{array}$ \\
\hline
\end{tabular}

Fonte: Autores.

A primeira categoria "Integrar educandos e formação do conhecimento", teve 11 citações e refere-se à importância de integrar os educandos, enquanto sujeitos que após sua formação devem trabalhar em equipe, e, além disso, 
contribui para a formação/compreensão do conhecimento pelos educandos, tal como podemos ver nos relatos dos educandos abaixo.

Aluno 1: "Aprendi a trabalhar melhor em grupo, a desenvolver técnicas de passar o conhecimento que obtive durante a produção dos trabalhos, e principalmente, a falar em público aquilo que aprendi”.

Aluno 2: "O que foi aprendido em aula na parte teórica a PPI traduz para a parte prática, mostrando para o aluno como essas novas técnicas e manejos devem ser empregados em casa ou na lavoura".

A partir dos relatos, é visível o quanto estes se preocupam com a construção dos seus conhecimentos, seja por meio do trabalho em grupo, como durante o decorrer da proposta. Além disso, os relatos vão ao encontro do que se refere Da Silva e Cenci (2015), que a relação com o meio ambiente, só poderá ser protegido dentro de uma visão coletiva e não individualista, que permita às presentes e futuras gerações usufruírem dos recursos naturais.

Na segunda categoria, "Importância e preservação da água" ressalta-se a importância do uso correto e consciente dos recursos naturais, já que estes são finitos e fundamentais para o desenvolvimento da vida, conforme foi destacado pelos educandos em seus relatos.

Aluno 3: "Aprendi que a água é um dos bens mais precioso que nós temos e devemos preservá-la o quanto pudermos".

Aluno 4: "Que necessitamos da água no nosso uso diário e também para meios de produção! "

A ênfase que se dá a importância e preservação da água por parte dos educandos, só afirma o quanto "o caminho do exercício permanente do pensamento crítico aprimora a aprendizagem pela conscientização e realização de experiências" (MACHADO; VESTENA; FOLMER, 2016, p. 13).

Na categoria C "Relações da água na agropecuária", apresentam-se relatos que remetem ao uso da água, sem discriminação de preservação e cuidados, apenas ressaltando o quanto este recurso natural é importante para os meios de produção.

Aluno 5: "Que a água é muito importante pra agropecuária".

Aluno 6: "Novas técnicas de manejo e integração de novas tecnologias na lavoura".

Partindo das respostas apresentadas pelos educandos, observa-se o reconhecimento que estes possuem sobre o uso da água na agropecuária, por ser um dos recursos mais utilizados pelo setor. Porém, há de se destacar que a agropecuária também é um dos setores que mais fazem o uso irracional da água, além de poluir rios, córregos e lençóis freáticos. Esse contexto de contaminação repercute sobre a maneira na saúde da população em geral e dos trabalhadores rurais em específico (FERREIRA et al., 2016, p. 748).

Diante a análise dos relatos, nota-se que ao pesquisarem, os alunos participam das decisões e podem buscar o conhecimento, de acordo com seus interesses, "assim eles têm mais abertura para aprofundar os conhecimentos 
que aprendem e de relacioná-los com suas experiências cotidianas" (CASANOVA; ALVES, 2013, p. 826).

Podemos exemplificar essa contextualização promovida pelos educandos na Figura 1, em que um dos grupos apresentou uma forma de reutilizar o óleo de cozinha descartado, utilizando-o como uma fonte de energia, transformando o mesmo em biodiesel. Na oficina apresentada, os alunos utilizaram o biodiesel produzido para abastecer o trator, e os mesmo fizeram uma demonstração prática do funcionamento do mesmo.

Figura 1 - Produção de biodiesel a partir do óleo de cozinha
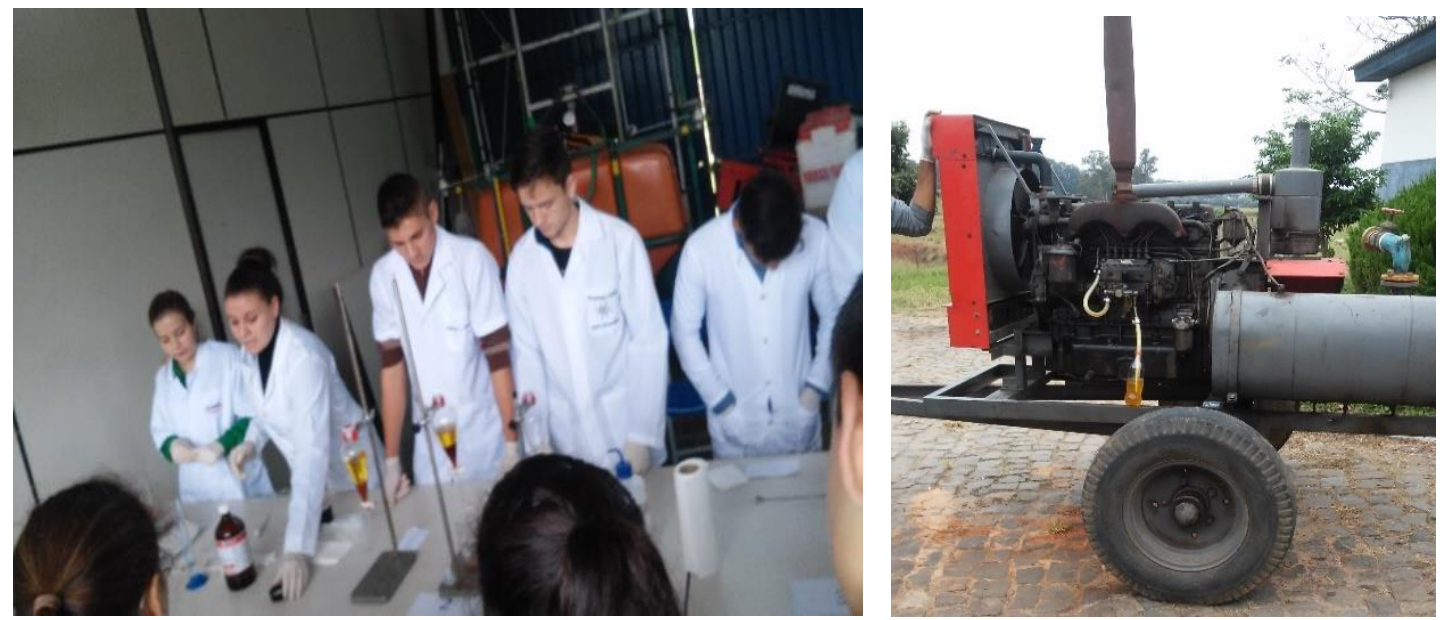

Fonte: Autores

Para Teixeira, Talamoni e De Campos (2013) o processo educativo é objeto da educação ambiental, na medida em que busca possibilitar que 0 conhecimento histórico prepare o homem para compreender suas necessidades e as do ambiente em que vive. Desta forma salientamos a importância da PPI na formação dos estudantes, como uma preparação para a realidade do contexto social em que vivemos, onde a preocupação com o meio ambiente deve ser colocada como prioridade.

Além disso, ressalta-se que as práticas educativas ambientalmente sustentáveis nos levam "às propostas pedagógicas centradas na criticidade e na emancipação dos sujeitos, com vistas às mudanças de comportamentos e atitudes, ao desenvolvimento da organização social e da participação coletiva" (JACOBI; TRISTÃO; FRANCO, 2009, P. 67).

\section{A Prática Profissional Integrada enquanto Formação Integral}

Buscando compreender de que maneira a PPI auxilia na construção dos conhecimentos, questionou-se aos educandos o "porquê a PPI era importante para a sua formação", logo, temos a Tabela 2 a seguir, que destaca as categorias geradas a partir das respostas obtidas. 
Tabela 2: A importância da PPI na formação profissional

\begin{tabular}{ll}
\hline Categorias & № de ocorrências \\
\hline \begin{tabular}{l} 
D) $\begin{array}{l}\text { Construção } \\
\text { conhecimento }\end{array}$ \\
\hline E) Relação teoria e prática
\end{tabular} \\
\hline $\begin{array}{l}\text { F) Integração } \\
\text { conhecimentos }\end{array}$ & dos 7 \\
\hline
\end{tabular}

Fonte: Autores.

Ao analisar a categoria D "construção do conhecimento", esta foi a mais destacada pelos educandos, uma vez que estes acreditam que a PPI auxilia na construção dos conhecimentos necessários para a formação profissional e humana, como pode ser vista nos relatos abaixo.

Educando 7: "É mais uma sabedoria e aprendizado na nossa vida e conhecimento educacional'.

Educando 8: "Ajuda no conhecimento técnico, facilita a comunicação com o público e nos motiva a realizar trabalhos em grupos". a vida".

Educando 9: "Porque serve para adquirirmos vários conhecimentos para

Diante destes relatos ressalta-se a importância em dar espaço ao aluno para que ele pesquise e exerça funções que reflitam de maneira positiva no seu cotidiano escolar. Particularmente, "no ensino de temas ambientais, há a necessidade de formar estudantes críticos que se sintam inseridos na sociedade, em projetos coletivos, que discutam e pesquisem as origens e os danos de agentes poluidores" (AUGUSTO, 2004. p. 279).

$\mathrm{Na}$ sequência, a categoria $\mathrm{E}$, "relação teoria e prática", reforça a proposta do ensino integrado, entrelaçando estas e acabando com a dicotomia encontrada por vezes. Além disso, esta deve "estender ao ensino médio processos de trabalho reais, possibilitando-se a assimilação não apenas teórica, mas também prática, dos princípios científicos que estão na base da produção moderna" (CIAVATTA, 2008, p. 05).

Partindo destes princípios, abaixo são apresentados relatos dos educandos que se enquadram nesta categoria.

Educando 10: "O que foi aprendido em aula na parte teórica a PPI traduz para a parte prática, mostrando para o aluno como essas novas técnicas e manejos devem ser empregados em casa ou na lavoura".

Educando 11: "Porque nela vimos coisas que as vezes são deixadas de lado em sala de aula".

Alguns fragmentos destes relatos apontam para alguns problemas do trabalho de sala de aula, onde os educandos afirmam que muitas vezes as aulas são apenas teóricas, não reforçando a relação da formação profissional 
com o que é trabalhado nas disciplinas. Logo, sabe-se que "essa reflexão sobre o trabalho como princípio educativo deve constituir-se em um movimento na busca da unidade teoria e prática" (MOURA, 2007, p. 22).

Por fim, a categoria $F$, "integração dos conhecimentos", destaca-se a presença da interdisciplinaridade, onde esta favoreceu um espaço de discussões em que se podem compartilhar as áreas de conhecimento e possibilitar um maior entendimento acerca das questões ambientais, como foi evidenciado nos relatos dos educandos a seguir.

Aluno 12: "aprendi assuntos primeiramente que não seriam dados na sala de aula, do mesmo modo que foi apresentado; que as matérias se ligam, nenhuma é independente".

Aluno 13: "Aprendi que integrando os conhecimentos qualquer conteúdo fica mais fácil e atrativo".

$\mathrm{Na}$ interdisciplinaridade escolar, as noções, finalidades habilidades e técnicas visam favorecer, sobretudo o processo de aprendizagem, respeitando os saberes dos alunos e sua integração (FAZENDA, 2008. p. 21). Durante todas as estações foi possível perceber a relação entre as disciplinas, e 0 quanto esta proposta resultou num bom desempenho ao final do semestre, onde os alunos obtiveram êxito no seu rendimento escolar.

Com isto, sugere-se o que descreve Saviani, em que "a produção do homem é, ao mesmo tempo, a formação do homem, isto é, um processo educativo" (2007, p. 154). Logo, as relações da construção do conhecimento, relação teoria e prática e a integração das áreas, possibilita uma formação profissional integral e humana.

Ao longo da discussão percebe-se o quanto os princípios do ensino integrado estão presentes no fazer da proposta, e como este processo repercute positivamente no posicionamento dos educandos, promovendo a autonomia e ampliando os conhecimentos.

\section{CONSIDERAÇÕES FINAIS}

Partindo dos conhecimentos abordados ao longo do texto foi possível verificar um maior interesse dos estudantes nas atividades propostas, tal fato se observou a partir da participação do mesmo durante o planejamento das atividades, havendo uma integração entre os conteúdos básicos com os técnicos. Assim possibilitando uma visão ampliada diante da teoria e a prática que os rodeiam, e ao mesmo tempo a aproximação dos conteúdos com a realidade.

A atividade de ensino integrada proporcionou a aproximação do estudante com a prática profissional e também uma maior preocupação quanto aos recursos hídricos. Desta forma, abriu-se a possibilidade para novas reflexões, olhares e atitudes, seguindo a premissa de que somos indivíduos que aprendem e ensinam (HOFSTATTER; DE OLIVEIRA; SOUTO, 2016. p. 630). 
Salienta-se a importância desta prática quanto a efetivação das bases da Educação Profissional e Tecnológica, onde, pode-se perceber o trabalho enquanto princípio educativo, a politecnia na educação, e a formação integrada, que juntos caracterizam uma formação omnilateral do sujeito.

Portanto, a PPI reforça que o educando deve ser um atuante em sala de aula, pois o maior objetivo da ação é propiciar que o mesmo construa seu próprio conhecimento, utilizando de seus conhecimentos empíricos associados às atividades propostas, ou seja, consiga criar relações da água com as demais disciplinas previstas, assegurando uma problematização social a qual proporciona uma maior reflexão quanto ao uso/desperdício abusivo da água.

\section{REFERÊNCIAS}

ARAUJO, Ronaldo Marcos de Lima; FRIGOTTO, Gaudêncio. Práticas pedagógicas e ensino integrado. Educação em Questão, v. 52, n. 38, p. 6180, 2015.

AUGUSTO, Thaís Gimenez da Silva; CALDEIRA, Ana Maria de Andrade. Dificuldades para a implantação de práticas interdisciplinares em escolas estaduais, apontadas por professores da área de ciências da natureza. Investigações em Ensino de Ciências, v. 12, n. 1, p. 139-154, 2016.

BACCI, Denise de La Corte; PATACA, Ermelinda Moutinho. Educação para a água. Estudos Avançados, v. 22, n. 63, p. 211-226, 2008.

BARDIN, Laurence. Análise de Conteúdo. 4ªed. Lisboa: Edições, v. 70, 2016.

BRASIL. Ministério da Educação e do Desporto. Secretaria da Educação Fundamental. Parâmetros curriculares nacionais: apresentação dos temas transversais, ética. Brasília, 1997.

BRASIL. (29 de dezembro de 2008). Lei no 11.892, de 29 de dezembro de 2008. Fonte: Instituto a Rede Federal de Educação Profissional, Científica e Tecnológica.: http://www.planalto.gov.br/ccivil_03/_ato20072010/2008/lei/l11892.htm.

CASANOVA, Marcello Paul; ALVES, José Moysés. Metas de realização e autoconceitos de estudantes de Ciências em contexto de ensino com pesquisa. Ciência \& Educação, v. 19, n. 4, p. 823-839, 2013.

CIAVATTA, Maria. A formação integrada à escola e o trabalho como lugares de memória e de identidade. Revista Trabalho Necessário, v. 3, n. 3, 2008.

CIAVATTA, Maria; RAMOS, Marise. Ensino Médio e Educação Profissional no Brasil: dualidade e fragmentação. Retratos da Escola, v. 5, n. 8, p. 27-41, 2012.

COUTINHO, Renato Xavier; FOLMER, Vanderlei e PUNTEL, Robson Luiz. Aproximando universidade e escola por meio do uso da produção acadêmica na sala de aula. Ciênc. educ. (Bauru). 2014, vol.20, n.3, p. 765-783. 
DA SILVA, Roberta Herter; CENCI, Daniel Rubens. Multiculturalismo e Educação Ambiental: reflexões acerca da construção de uma nova postura ética dos seres humanos. Revista Contexto \& Educação, v. 30, n. 97, p. 6793, 2015.

DE SANTANA, Aline Neves Vieira; DE SOUZA, Leandro Nunes; SHUVARTZ, Marilda. Análise do tema água em livros didáticos de ciências do ensino fundamental. 2012.

ENGEL, Guido Irineu. Pesquisa-ação. Educar em Revista, n. 16, p. 181-191, 2000.

FAZENDA, Ivani C. A. O Que é interdisciplinaridade? São Paulo: Cortez, 2008.

FERREIRA, Marcelo José Monteiro et al. Gestão e uso dos recursos hídricos e a expansão do agronegócio: água para quê e para quem?. Ciência \& Saúde Coletiva, v. 21, p. 743-752, 2016.

GERHARDT, Tatiana Engel; SILVEIRA, Denise Tolfo. Métodos de Pesquisa. Coordenado pela Universidade Aberta do Brasil - UAB/UFRGS e pelo Curso de Graduação Tecnológica - Planejamento e Gestão para o Desenvolvimento Rural da SEAD/UFRGS. - Porto Alegre: Editora da UFRGS, 2009.

HOFSTATTER, Lakshmi Juliane Vallim; DE OLIVEIRA, Haydée Torres; SOUTO, Francisco José Bezerra. Uma contribuição da educação ambiental crítica para (des) construção do olhar sobre a seca no semiárido baiano.

Ciência \& Educação (Bauru), v. 22, n. 3, p. 615-633, 2016.

INSTITUTO FEDERAL FARROUPILHA. Projeto Pedagógico Do Curso Técnico Em Agropecuária Integrado Ao Ensino Médio. Campus São Vicente do Sul. São Vicente do Sul/RS - Brasil. 2014.

JACOBI, Pedro Roberto; TRISTÃO, Martha; FRANCO, Maria Isabel G. C. A função social da educação ambiental nas práticas colaborativas: participação e engajamento. Cadernos CEDES, v.29, n.77, p.63-79, 2009.

MACHADO, Gabriella Eldereti; VESTENA, Natana Pozzer; FOLMER, Ivanio. $(R e)$ uso da água da chuva: experiência no Colégio Politécnico de Santa Maria (RS). Revista Brasileira de Educação Ambiental (RevBEA), v. 11, n. 5, p. 10-18, 2016.

MOURA, Dante Henrique. Educação básica e educação profissional e tecnológica: dualidade histórica e perspectivas de integração. Holos, v. 2, p. 430, 2007.

OTALARA, Aline Piccoli; CARVALHO, Luiz Marcelo de. O tema água nos livros didáticos de ciências da natureza, o cotidiano (global-local) e as questões ambientais. VI Encontro "Pesquisa em Educação Ambiental" A Pesquisa em Educação Ambiental e a Pós-Graduação no Brasil, 2011.

QUADROS, Ana Luiza. A Água como tema gerador do conhecimento químico. Química nova na escola, n² 20, p. 26-31, 2004.

SAVIANI, Dermeval. Trabalho e educação: fundamentos ontológicos e históricos. Revista brasileira de educação, v. 12 n. 34 jan./abr, 2007. 
SCHWARZ, Maria Luiza et al."Chuva, como te queremos!”: representações sociais da água através dos desenhos de crianças pertencentes a uma região rural semiárida do México. Ciencia \& Educação, v. 22, n. 3, p. 651-669, 2016. TEIXEIRA, Lucas André; TALAMONI, Jandira Líria Biscalquini; DE CAMPOS, Marília Freitas Tozoni Reis. A relação teoria e prática em projetos de educação ambiental desenvolvidos em um bairro de Bauru, SP, Brasil. Ciencia \& Educação, v. 19, n. 3, p. 657-676, 2013.

THIOLLENT, Michel. Metodologia de Pesquisa - Ação. 16. ed. São Paulo: Cortez, 2008. 